\title{
Correction: Discontinuing disease-modifying therapy in MS after a prolonged relapse-free period: a propensity score-matched study
}

Kister I, Spelman T, Alroughani R, et al. Discontinuing disease-modifying therapy in MS after a prolonged relapse-free period: a propensity score-matched study. J Neurol Neurosurg Psychiatry 2016;87:1133-7. doi: 10.1136/jnnp-2016-313760

In this article there was a discrepancy between the text and figure $1 \mathrm{~A}$ and $\mathrm{B}$. The published version is based on preliminary analyses based on 1:1 match, while they present results of our final analysis based 1:2 propensity score match. The correct version of figure $1 \mathrm{~A}$ and $\mathrm{B}$ are below.

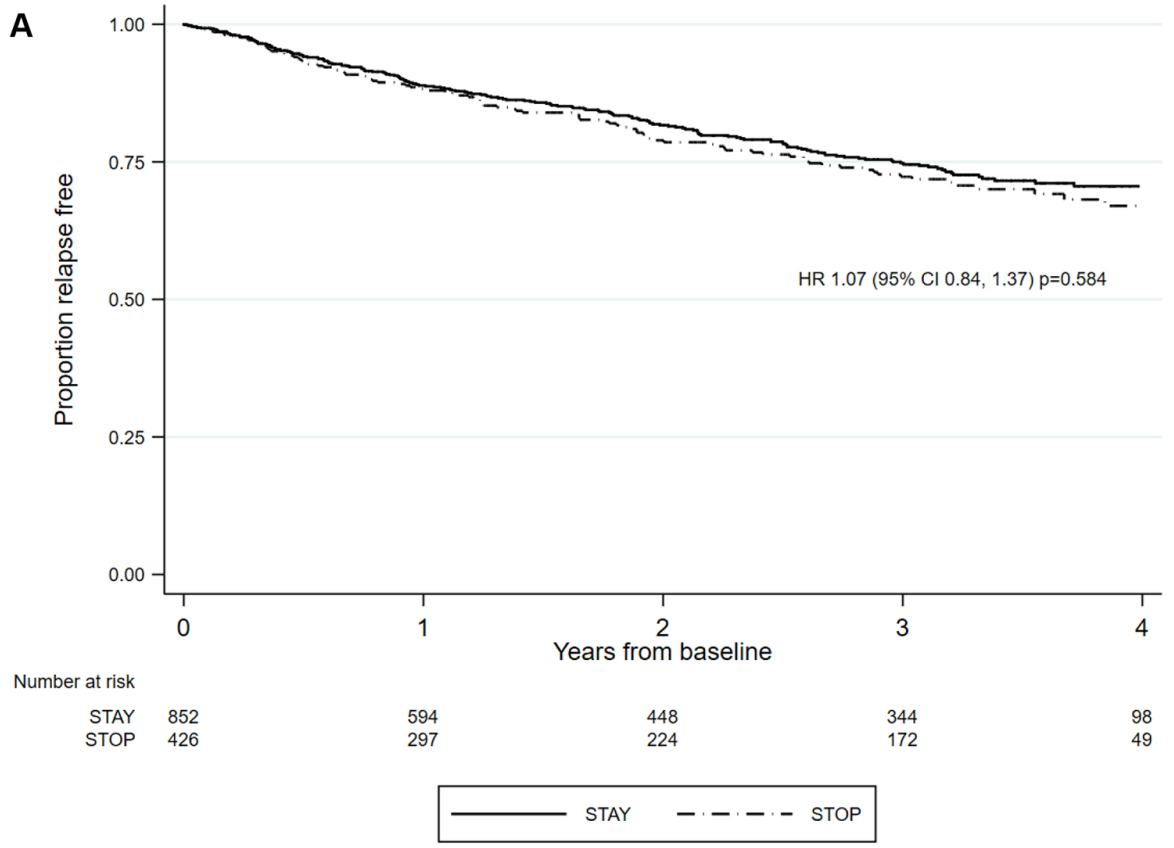

B

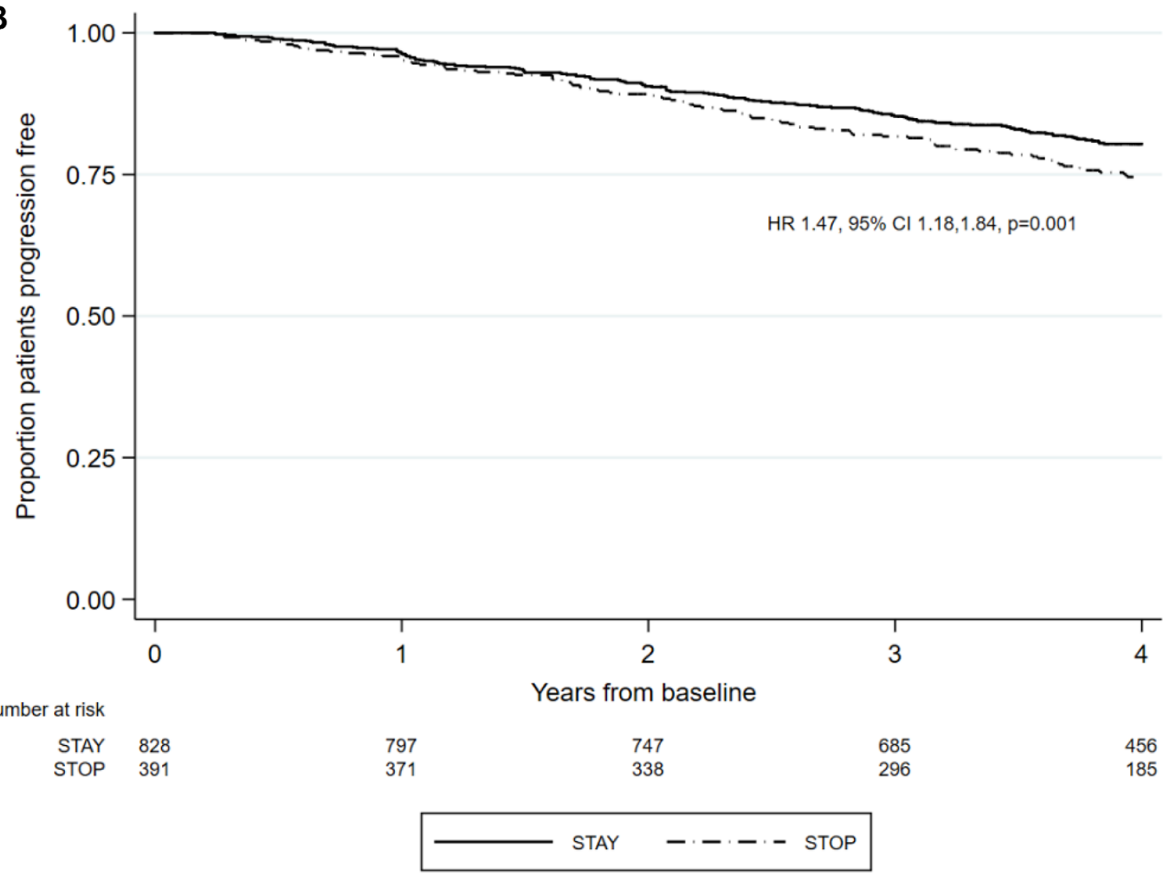

(C) Author(s) (or their employer(s)) 2019. No commercial re-use. See rights and permissions. Published by BMJ.

J Neurol Neurosurg Psychiatry 2019;90:e2. doi:10.1136/jnnp-2016-313760corr1

A) Check for updates 